\title{
Orthopedic Injuries in Poly- Traumatized Patients in Age Group of 15-45 Years
}

\author{
Muddather AA. Mohammed, Omar MS. Younus, Ahmad Saladdin Sultan
}

Emergency Medicine, Scientific Council of Emergency Medicine

Corresponding author: Ahmad Saladdin Sultan; Email: dr.ahmad1981@gmail.com

\begin{abstract}
Background: Orthopedic injuries in polytraumatised patient are common and affect the management in such patients. Aim of the Work: The purpose of this study was to assess the pattern and nature of orthopedic injuries in polytraumatised patient who sustain different mechanism of injury and to analyze the management of these injuries in the E.D. It is a descriptive study carried out at E.D. of Al-Jamhory teaching hospital. Patients and Methods: The study included all polytraumatised patient aged 15-45 years admitted to the E.D. OF Al-Jamhory teaching hospital after being injured in different mechanism of injury (MCV, FFH, Bullet injury, ... etc). Management carried out according to ATLS and to specific patient needs, 64 patient included in this study by using a special form for the study, patients ages were ranging from 15-45 years with subdivided to subgroups (15-25), (26-35), (36-45) and studied separately from the mechanism of injury and injured part of the body point of view. Results: Total number of causalities was 64 their mean age was 20 years, out of them 59 were male and 5 females, the most mechanism of injury were MVC 32(50\%), transportation time was with average of 30 minutes, upper limbs affected equally to lower limbs, closed orthopedic injuries were common than open injuries, head injuries were noted to be the bulk associated injuries with the most serious and fatal outcome. Conclusions: Orthopedic injuries have a major impact on the management of polytraumatized patients. Males were the active sex group in our society and had much more affected in polytrauma than females with the main mechanism of injury of MVC.
\end{abstract}

Key words: Motor vehicle collision, polytrauma patient, orthopedic injury

\section{INTRODUCTION}

Damage control orthopedic: Damage control in general trauma surgery includes packing the major sources of haemorrhage rather than performing immediate, lengthy, definitive procedures of the visceral organs. As part of the damage control philosophy, immediate life-saving interventions, directed at stopping bleeding are applied, after which resuscitation and further stabilization are performed in the ICU. Only after the overall physiology has improved definitive interventions are performed. This change in trauma practice resulted in improved survival rates. Initial surgery was done with the goal of achieving rapid skeletal stabilization of major orthopaedic injuries to stop the cycle of ongoing musculoskeletal injury and to control haemorrhage. This approach was termed "Damage Control Orthopaedics"(1).

The Advanced Trauma Life Support (ATLS) course teaches a systematic, concise approach to the early care of the trauma patient. This course is vital to guiding care for the injured patient in emergency department trauma rooms. ATLS course training provides a common language that can save lives in critical situations ${ }^{(2)}$.

The management of the multiply-injured patient has been revolutionized during the past century. Advances in prehospital care, resuscitation, implants and intensive-care medicine have all contributed to better treatment of the patient in physiological crisis after trauma, who is at risk for the multiple-organ dysfunction syndrome and is battling for survival ${ }^{(\mathbf{1})}$.

The implementation of advanced trauma life support training was probably the greatest stimuli affecting the philosophy in the treatment of patients with polytrauma. However, more recent development in molecular medicine and genetics have influenced our perception of management leading to the concept of "damage control procedures" (1). While the basic concept of 'save lifelimit disability' has not changed, the type and timing of interventions have been gradually modified ${ }^{(\mathbf{1})}$.

The vast majority of patients sustaining polytrauma have some form of musclo-skeletal injury, these injuries often cause significant pain \& may distract from other more life-threatening injuries, even though extremity injuries can threat in the long term function or even survival of a limb they rarely constitute an acute life threat ${ }^{(2)}$.

Wound management is of great important in proper healing of penetrating and crush injuries, careful treatment is, however, just one important factor in decreasing the rate of wound infection, bacterial inoculums, tissue devitalization, blood supply, time to presentation and treatment, presence of foreign bodies and host immune status, all play a role in final outcome. ${ }^{3}$ 
The most important component of wound management and prevention of infection is irrigation, the technique require copious amount of fluid (500$1000) \mathrm{cc}$ at high pressure (15-20 pounds per square inch)this can be achieved by using $60 \mathrm{ml}$ syringe with 18 gauge catheter or wound irrigator. ${ }^{3}$ The solution should be either saline or tap water, antiseptic solution does not decrease infection rate or improve healing time and may be harmful, more vigorous and lengthily irrigation may be needed for heavily contaminated wounds. In wounds older than 3 to 4 hours gentle scrubbing of the wound is recommended ${ }^{(3)}$.

Vascular injury is a major complication of military and civilian trauma. Major developments in this field have been related to military conflicts during the past 100 years ${ }^{(4)}$.

Trauma has become a public health problem in many parts of the world, and vascular trauma is an important component of this problem, however, the mechanism of injury seems to differ between different parts of the world. While successful treatment of major arterial injuries may be life-saving as well as allowing limb salvage and restoration of function ${ }^{(4)}$.

The diagnosis of an extremity vascular injury is initially made by physical examination as part of the full trauma assessment. The classic five P's:-pain, pulselessness, pallor, paresthesia and paralysis may be partially present or may be absent in many patients. Some patients with axillary and proximal brachial artery injuries may have palpable pulses at the wrist. The injury type and location are noted, and the axillary, brachial, radial and ulnar arteries are palpated for pulsations. Depending on the mode of presentation, most patients were taken immediately to the operating room for vascular or orthopedic/vascular management ${ }^{(4)}$. In others with soft signs or doubtful vascular injury (especially with hematoma, compartmented limb or for medico-legal reasons) and when patients were stable, preoperative duplex ultrasonography /angiography were performed ${ }^{(4)}$.

All patients with associated orthopedic injury underwent reduction of joint dislocation or bone fracture and immobilization by internal or external fixation, it always preceded vascular repair unless the extremity was threatened and required immediate revascularization ${ }^{(4)}$. Repaired vessels especially at the anastomotic suture lines and graft location, were compulsory covered with muscles and soft tissues to prevent desiccation and disruption. In all patients management of vascular injuries was performed in the operating room under general anesthesia using standard vascular techniques. Depending on the condition of the limb after revascularization, open full fasciotomy was carried out liberally to either relieve existing compression or to avoid one from occurring in the postoperative period ${ }^{(\mathbf{4})}$.

The principle of fractures treatment in polytrauma is to achieve stable osteosynthesis which will allow early mobilization ${ }^{(5)}$. Fractures with a concomitant vascular injury or compartment syndrome have the first priority for treatment followed by open fractures and joint injuries, the most important prognostic factors for fractures with vascular lesions are the ischemic interval and the degree of any reperfusion disturbances. Muscles lose their function after two to four hours of ischemia; irreversible destruction may develop after four to six hours. Nerve tissue loses some function after 30 minutes, and irreversible injuries can develop after 12 to 14 hours of complete ischemia. In the blood vessels, severe changes in capillaries and the endothelium are seen after three hours of ischemia. These result in changes in permeability of the capillary bed, leading to post-ischemic swelling of the soft tissues in $30 \%$ to $60 \%$ of cases. This damage is aggravated in multiply-traumatized patients with generalized hypoxemia ${ }^{(5)}$.

Vascular injury therefore requires prompt diagnosis and direct treatment. Reconstruction of the arterial lesion has first priority, and in cases in which an immediate repair is difficult, the use of a temporary shunt should be considered ${ }^{(5)}$.

Some regions are particularly susceptible to vascular injuries. These include the subclavian artery near the clavicle and the brachial artery near the shaft of the humerus. The femoral artery in the region of the femoral shaft and the popliteal artery at the knee are also in danger because of their fixation to bone. Dislocation of the knee involves rupture of vessels in about50\% of cases ${ }^{(5)}$.

Hemorrhage from limb injuries has been identified as the most important cause of avoidable battlefield death, The treatment paradigm has shifted in the UK military from ABC(airway, breathing, circulation) to $\langle\mathrm{C}\rangle \mathrm{ABC}$ to reflect the importance of rapidly controlling external hemorrhage, this concept is firmly embedded in training at all levels of provider in the early management of severe trauma, $1^{\text {st }}$ by direct pressure which is the initial measure to be taken to arrest the active bleeding, Commercial tourniquet sare issued 
to individual deploying soldiers as part of their personal first aid equipment with encouragement to use the device for severe limb bleeding during care under fire and to immediatelyre-evaluate the requirement when the fire-fight is won(tactical field care phase). ${ }^{6}$ This is pictorially represented in the haemostasis ladder, an escalator of interventions for uncontrollable hemorrhage. However, the use of tourniquets on traumatic amputations has been criticized as contributing to unnecessary limb loss ${ }^{(\boldsymbol{6})}$.

The treatment of wounds of open contaminated fractures was augmented by external fixation, this lead to quick fractures stabilization, stability for fractures repairs, and access to the wound debridement and subsequent soft tissue surgery ${ }^{(7)}$.

Many orthopedic patients who have sustained multiple injuries benefit from the early total care of major bone fractures. However, the strategy is not the best option, and indeed might be harmful, for some multiply injured patients ${ }^{(8,9)}$.

Since foregoing all early surgery is not the optimal approach for those patients, the concept of damage control orthopedics has evolved ${ }^{(8)}$. Damage control orthopedics emphasizes the stabilization and control of the injury, often with use of spanning external fixation, rather than immediate fracture repair ${ }^{(9)}$. The concept of damage control orthopedics is not new; it has evolved out of the rich history of fracture care and abdominal surgery ${ }^{(9)}$. Tracing the roots of damage control orthopedics, reviewing the physiologic basis for it, describing the subgroups of patients and injury complexes that are best treated with damage control orthopedics, reporting the early clinical results, and providing a rationale for modern fracture care for the multiply injured patient ${ }^{(9)}$.

\section{AIM OF THE WORK}

The current study aimed at: Studying the orthopedic injuries in polytraumatised patients and their management in the ED. Evaluating the distribution of patients according to age, sex, mechanisms of injury and to evaluate the associated injuries and their impact on each other.

\section{PATIENTS AND METHODS}

The present study included 64 patients aged between 15 years to 45 years who presented to ED in Al-Jamhory teaching Hospital in Mosul City with polytrauma injuries including orthopedic injuries during the period from October 2010 to July 2011. The study was approved by the Ethics Board of Al-Jamhory teaching Hospital.

Each patient was examined according to the following criteria: (age, sex, mechanism of injury; type of orthopedic injury \& associated injuries, clinical \& radiographic assessment of injuries \& treatment).

Full clinical investigation on each patient was performed including; vital signs(blood pressure, pulse rate and respiratory rate), as well as complete assessment according to ATLS protocol, radiographical assessment also carried out including: CT-scanning of head(brain \& bone window), chest $\mathrm{X}$-ray, also imaging technique including FAST examination of the abdomen.

The treatments of the patients in the emergency department included: resuscitation, wound care, treatment of fractures. Special form was designed to record the data of the studied samples. This is descriptive study mentioned in number and percentage of the results shown in tables and figures.

\section{RESULTS}

Of the 64 patients included in the study, 59 (92.2\%) were males and 5 (7.8\%)were females, their distribution according to the mechanism of injury shown in table -1-, the main mechanism was motor vehicle collision for both genders and followed by fall from height.

Table (1): Mechanism of injury \& No. percentage of male $\&$ female in each type of injury.

\begin{tabular}{|l|c|c|c|c|c|c|}
\hline \multirow{2}{*}{$\begin{array}{c}\text { Mechanism } \\
\text { of injury }\end{array}$} & \multicolumn{7}{|c|}{ No. of patients } \\
\cline { 2 - 7 } & Total & $\%$ & Male & $\%$ & female & $\%$ \\
\hline $\begin{array}{l}\text { Motor vehicle } \\
\text { accident MVC }\end{array}$ & 32 & $50.0 \%$ & 30 & $93.7 \%$ & 2 & $6.2 \%$ \\
\hline $\begin{array}{l}\text { Fall from } \\
\text { height }\end{array}$ & 12 & $18.7 \%$ & 11 & $91.7 \%$ & 1 & $8.3 \%$ \\
\hline Blast injury & 10 & $15.6 \%$ & 9 & $90.0 \%$ & 1 & $10.0 \%$ \\
\hline Bullet injury & 9 & $14.0 \%$ & 8 & $88.9 \%$ & 1 & $11.1 \%$ \\
\hline $\begin{array}{l}\text { Industrial } \\
\text { injury }\end{array}$ & 1 & $1.6 \%$ & 1 & $100 \%$ & 0 & $0.0 \%$ \\
\hline Total & 64 & $100 \%$ & 59 & $92.2 \%$ & 5 & $7.8 \%$ \\
\hline
\end{tabular}

According to age group and in association with mechanism of injury, the most injured age group fall on (15-25years) with most of them injured by motor vehicle collision, followed by the (26-35years) group with also motor vehicle collision was the main mechanism of injury and followed by bullet injury table-2-. 
Table (2): Mechanisms of injuries according to age group.

\begin{tabular}{|c|c|c|c|c|c|c|c|c|c|c|}
\hline $\begin{array}{c}\text { Age } \\
\text { group } \\
\text { (years) }\end{array}$ & MVC & №.\% & F.F.H & No.\% & \begin{tabular}{|c|} 
blast \\
injury
\end{tabular} & No.\% & $\begin{array}{l}\text { Bullet } \\
\text { injury }\end{array}$ & No.\% & $\begin{array}{c}\text { Industrial } \\
\text { injury }\end{array}$ & No.\% \\
\hline $\begin{array}{l}15-25 \\
\text { vears }\end{array}$ & 13 & $40.6 \%$ & 4 & $33.3 \%$ & 3 & $30.0 \%$ & 7 & $77.8 \%$ & - & -- \\
\hline $\begin{array}{l}26-35 \\
\text { years }\end{array}$ & 13 & $40.6 \%$ & 4 & $33.3 \%$ & 4 & $40.0 \%$ & 1 & $11.1 \%$ & 1 & $100 \%$ \\
\hline $\begin{array}{l}36-45 \\
\text { years }\end{array}$ & 6 & $18.7 \%$ & 4 & $33.3 \%$ & 4 & $40.0 \%$ & 1 & $11.1 \%$ & - & -- \\
\hline Total & 32 & $100 \%$ & 12 & $100 \%$ & 10 & $100 \%$ & 9 & $100 \%$ & 1 & $100 \%$ \\
\hline
\end{tabular}

Time consumed for transportation from the scene to the emergency department was from $15 \mathrm{~min}$. up to 1 hour with average mean time of 30 minutes.

The thirty two patients whose the mechanism of injury is collision subdivided according to their situation at time of accident of those 11(34.3\%) were drivers, $12(37.5 \%)$ were passengers and $9(28.1 \%)$ were pedestrians, figure 2 .

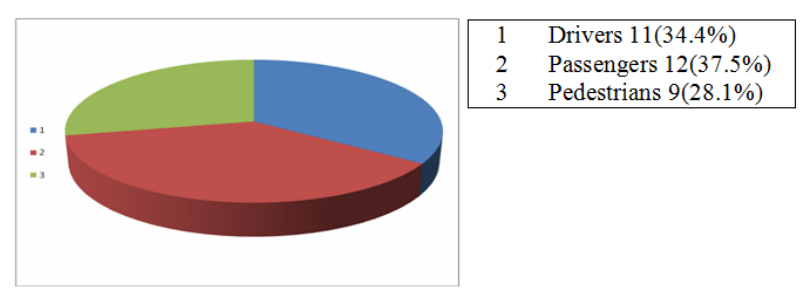

Figure (4): States of injured patients in MVC

Upper extremities injuries seen in $31(48.4 \%)$ patients while lower extremities injuries seen in 30 (46.87\%) patients and mixed upper and lower limbs injuries was found in 3(4.7\%) patients only. In upper limbs injury $25(39.1 \%)$ were closed injury and $6(9.37 \%)$ were open injuries.

Of lower limbs injuries 17(26.6\%) patients were with closed injury, $13(20.3 \%)$ patients were with open injury and lastly the $3(4.7 \%)$ patients of both upper and lower injuries had open injury.

The total number of patients with closed injury were $42(65.6 \%), 3(4.68 \%)$ of them were arrived the emergency department in shock status, 39 $(60.93 \%)$ were heamodynamically stable, the patients with open injuries were all 22(34.4\%), 18(28.1\%) in shock and only $4(6.3 \%)$ were heamodynamically stable.

Resuscitation took place according to ATLS protocols, air-way management needed in $10(15.6 \%)$ patients, all of them had head injury, $8(80.0 \%)$ patients managed by endotracheal intubation and one patient underwent cricothyrotomy and another managed by nasopharyngeal airway, all patients resuscitated by intravenous fluids (N/S $0.9 \%$, or ringer lactate) with majority for $\mathrm{KVO}$ rate, the $21(32.8 \%$ )shocked patients treated by $1500-2500 \mathrm{cc}$ of intravenous fluids, $6(28.6 \%)$ patients underwent blood transfusion to complete the resuscitation.

The associated injuries were studied according to their affected anatomical region and in relation with the mechanism of injury in $56(87.5 \%)$ patients shown in table -6-with the most significance for head injury followed by the abdominal injury with most of them caused by motor vehicle collision followed by fall from height, Figure-4-.

Table (3): Injury associated with orthopedic injury in polytraumatised patient.

\begin{tabular}{|l|c|c|c|c|c|c|c|c|c|}
\hline $\begin{array}{c}\text { Mechanism } \\
\text { of injury }\end{array}$ & $\begin{array}{c}\text { Total } \\
\text { no. }\end{array}$ & $\begin{array}{c}\text { Head } \\
\text { injury }\end{array}$ & no.\% & $\begin{array}{c}\text { Chest } \\
\text { injury }\end{array}$ & no.\% & $\begin{array}{c}\text { Abdominal } \\
\text { injury }\end{array}$ & no.\% & $\begin{array}{c}\text { C- } \\
\text { spine } \\
\text { injury }\end{array}$ & no.\% \\
\hline MVC & 26 & 19 & $73.1 \%$ & 3 & $11.5 \%$ & 3 & $11.5 \%$ & 1 & $3.9 \%$ \\
\hline FFH & 12 & 10 & $83.3 \%$ & 0 & $0.0 \%$ & 2 & $16.7 \%$ & 0 & $0.0 \%$ \\
\hline Blast injury & 10 & 5 & $50.0 \%$ & 0 & $0.0 \%$ & 5 & $50.0 \%$ & 0 & $0.0 \%$ \\
\hline Bullet injury & 7 & 0 & $0.0 \%$ & 4 & $57.1 \%$ & 3 & $42.9 \%$ & 0 & $0.0 \%$ \\
\hline Industrial & 1 & 0 & $0.0 \%$ & 1 & $100.0 \%$ & 0 & $0.0 \%$ & 0 & $0.0 \%$ \\
\hline
\end{tabular}

The remaining $8(12.5 \%)$ patients whose suffered multiple injuries beside the orthopedic element of injury discussed as there were $4(50.0 \%)$ patients had head and chest injuries, 3(37.5\%) patients sustain chest and abdominal injuries, the last patient suffered from head, Cervical spine and chest injuries, all of them resulted from motor vehicle collision except 2 patients from bullet injury of head and chest injuries.

Orthopedic injuries treated conservatively in the ED by splinting in $52(81.2 \%)$ patients and 12 (18.7\%) patients had operated on, $6(50.0 \%)$ of them had soft tissue injuries were wound debridement was done for them, 5 (41.7\%) patients underwent external fixation which is damage control orthopedic management and only $1(8.3 \%)$ patient was treated with closed reduction.

Nine $(14.1 \%)$ patients admitted to the ICU, $7(77.8 \%)$ of them had chest injury and $2(22.2 \%)$ had head injury (one of them died in the 1 st 24 hour), the rest $55(85.9 \%)$ of patients were admitted to the surgical ward and then treated accordingly.

\section{DISCUSSION}

In this study most of the patients were males and specially in age group of (15-25) years with the mean age of 20 years and that was in contrast to other study conducted by Malczyk et al. ${ }^{(10)}$, were the 
females had high number in polytrauma patients \& the ages distributed over (14-45) years fairly and this belonged to that the minority of females are drivers in our country in comparison to outside. Also, it is probably because of the preventive rules in our society concerning the affairs dealing with women.

It is obviously that motor vehicle collision had the highest percentage in causing polytrauma injuries for civilian accident. This conclusion agree with that found by Malczyk et al. ${ }^{(\mathbf{1 6})}$, who showed high-speed impacts from road traffic accident are a major cause of polytrauma.

Most of the collision's patients were passengers and to less extent drivers with no safety profiles (lake of seat belt application compliance and traffic rules also air bags lake cars), this is beside the impact severity and collision configuration the protection of the occupant with seat belt and airbags is of importance ${ }^{(\mathbf{1 0})}$.

Time plays a major role in the salvage rate for the polytraumatised patient especially the transportation from the scene to emergency department. In this study average time was about 30minute, this point discussed in Hall Carmen where the average time of arrival is about 30 minutes in dependence of EMS transportation in comparison to our study where the transportation take on civilian and military vehicles.

Most of the patients had either upper or lower limbs injury approximately in same percentage with minor group had mixed both upper and lower injuries., and this agree with that found by Hall Carmen ${ }^{17}$, who indicated that the major involved part of the body in the polytrauma are the limbs.

Two third of the patient in this study found to have closed orthopedic injury which concur with the finding of Malczyk et al. ${ }^{(10)}$ and Carmen ${ }^{(11)}$ where the type of fracture depends mainly on the mechanism of injury and that is clear about our locality where the explosions falls to less degree. it is obvious that the main mechanism of injury during the period of the study was the $\mathrm{MVC}^{(\mathbf{1 0 , 1 1}, \mathbf{1 2})}$.

The most associated injury in this study was head injury in association with orthopedic injury and this is in reverse to other study shown in Carmen study ${ }^{(11)}$ where the thoracic injury was the most, this may be because direct impact of head on front of the car because the seat belt was not used in our society like others where the belt cause mainly chest injury ${ }^{(11,13,14,15)}$.

All of the patients treated conservatively in the ED with pending definitive treatment accordingly later on, with most of the patients had splinting by plaster of paris mainly or skin traction, others submit external fixation to maximize the healing process.

\section{CONCLUSION}

The current study concluded the following points: MVC is the main mechanism of injury in causing polytrauma with orthopedic injury. Males affected more predominantly than females in polytrauma. The most serious injuries in combination with orthopedic injury is head injury in our study with the highest percentage and most fatal. Chest injury in polytrauma patient impedes the early total care of orthopedics injuries.

\section{REFERENCES}

1. Giannoudis PV (2003): Aspects of current management. Surgical priorities in damage control in Polytrauma. The journal of bone and jount Surgery, 4: 478-483.

2. Tintinalli JE (2011): Emergency Medicine, A comprehensive study guide. 7th Ed. McGrawHill.

3. Bisano $M$, Bachia $K$ and Filbin $M$, Atls $R$ (2010): Emergency Medicine of the Trauma PatientOrthopade.,39(8): 771-6.

4. Raafat C, Al Amri Y, Khoujah E (2006): Vascular injuries of the upper extremity, $\mathrm{J}$ Vasc Bras, 5(4): 271-276.

5. Tscherene H, Regel G (1996): Care of the polytraumatised patient.The journal of bone and JountSurgery, 78(5): 840-852.

6. Brodie S, Hodgetts T, Ollerton J, McLeod J, Lambert $P$ and Mahoney $P$ (2010): JR Army Med Corps, 153(4):310-313.

7. Malik Z, Salim M, Perves M, Hanif M, Tariq $M$ andSafdar $T$ (2009): Management of gunshot and blast injuries after a suicidal terrorist attack in a closed space. J Pak Orthop Assoc., 21(1):55-61.

8. Hans P, Hildebrand F, Pertschy S, Zelle B, Garapati R, Grimme $\mathrm{K}$ and Krettek $\mathrm{C}$ (2002): Changes in the Management of 
Femoral Shaft Fractures in Polytrauma Patients: From Early Total Care to Damage Control Orthopedic Surgery", The Journal of Trauma_ Injury, Infection, and Critical Care, 53(3): 452-462.

9. Roberts CS, Pape HC, Jones AL, Malkani AL, Rodriguez JL, Giannoudis PV (2005): Damage control orthopaedics: evolving concepts in the treatment of patients who have sustained orthopaedic trauma. JBJS., 87(2): 434-49.

10. Malczyk A, Edgar M, Michael E, Tobias S, Carla W, Lorenz L, Matthias H, Martin K, Linda W, Florian $G$ and Ulrich $L$ (2011): Car Crashes With Polytrauma In Southern Germany. Available at: https://www-nrd.nhtsa. dot. gov/ pdf/ esv/ esv21/09-0400.pdf

11. Carmen H, Linda M (2008): QUERI currently focuses on nine conditions that are prevalent and high-risk among veterans: Chronic Heart Failure, Diabetes, HIV/ Hepatitis, Ischemic Heart Disease, Mental Health, Polytrauma and Blast-Related Injuries, Spinal Cord Injury, Stroke, and Substance Use Disorders. Polytrauma and blast-related Injuries. Available at: https:// books. google. com. eg/ books?id=MUItoTour5o.

12. Eker HH, Van Lieshout EM, Den Hartog D, Schipper IB (2010): Trauma mechanisms and injuries associated with go-karting. The open orthopaedics journal, 4: 107.

13. Hartl R, Gerber L, lacono L, Ni Q, Lyons J (2006): Direct transport within an organized state trauma system reduces mortality in patients with severe traumatic brain injury, The journal of trauma injury, infection and critical care, J trauma, 60: 1250-1256.

14. Di Bartolomeo S (2011): The 'off-hour' effect in trauma care: a possible quality indicator with appealing characteristics. Scandinavian journal of trauma, resuscitation and emergency medicine, 19(1): 33.

15. Upadhyay RP (2012): An overview of the burden of non-communicable diseases in India. Iranian journal of public health, 41(3): 1 .
16. White T, Petrisor BA, Bhandari M (2006): Prevention of fat embolism syndrome. Injury, 37(4): S59-67.

17. Nathan ST, Roberts CS and Deliberato D (2012): Lumbar paraspinal compartment syndrome. International orthopaedics, 36(6):1221-7.

18. Payo J, Foruria A, MunueraL and GilGaray E (2008): "Treatment of musculoskeletal injuriesof multiple-trauma patients in a Spanish tertiaryreferral hospital", Rev. Esp. Cir. Ortop. Traumatol., 52: 137-144.

19. Selvakumar R (2009): Timing of fractures fixation in polutrauma patient anesthesiologist's perspectives, JAAOS., 17(9): 541-9.

20. Wills S, Pandian G, Bhanu T, Kumar K, Murugan Y, Abhilash K (2016): Clinical profile of patients with traumatic cervical spine injury in the emergency department of a tertiary care hospital. Journal of Emergencies, Trauma and Shock, 9(1): 441-455.

21. Stiell IG, Clement CM, McKnight RD, Brison R, Schull MJ, Rowe BH, Worthington JR, Eisenhauer MA, Cass D, Greenberg G, MacPhail I (2003): The Canadian C-spine rule versus the NEXUS lowrisk criteria in patients with trauma. New England Journal of Medicine, 349(26):2510-8. 